\title{
Effects of Mode and Duration of Exercises on Fat Mass of Obese Population
}

\author{
Batool Hassan, Sumaira Imran Farooqui, Muhammad Usman Khan, Ali Farhad and Qurat UI Ain Adnan \\ Ziauddin College of Rehabilitation Sciences, Ziauddin University, Karachi, Pakistan
}

\begin{abstract}
A meta-analysis was performed to determine impact of resistance and aerobic exercise on body fat of obese population. Database of Google Scholar, BioMed Central, and Medline was reconnoitered for the purpose of research article of interest. Inclusion criteria encompass all those studies in which effects of aerobic and resistance exercise were determined on body fat mass of obese participants. Studies in which combination of aerobic and resistance exercise were used, or outcome measures were other than body fat mass or studies conducted before 2010 were excluded from this review. A total of 805 obese participants were included in 10 randomized controlled trials (RCT) including 401 in resistance training protocol and 404 in aerobic training protocol were part of this meta-analysis. Results revealed that resistance exercise had a mild pool affect in increasing weight of participants with an effect size (SMD) of 0.26 ( $95 \%$ of $\mathrm{Cl}-0.09$ to 0.63 ) calculated at random effect model, $\mathrm{I}^{2} 83.80 \%$ ( $95 \%$ of $\mathrm{Cl} 71.76$ to 90.71 ) in comparison to aerobic exercises performed during the duration of two to eight weeks of training protocol. The meta-analysis concluded that resistance exercises had a mild pool effect in increasing the weight of the participants in comparison to aerobic exercises.
\end{abstract}

Key Words: Aerobic exercises, Resistance exercises, Obesity, Fat mass, Body fat index and body fat composition.

How to cite this article: Hassan B, Farooqui SI, Khan MU, Farhad A, Adnan QUA. Effects of Mode and Duration of Exercises on Fat Mass of Obese Population. J Coll Physicians Surg Pak 2020; 30(04):412-416. DOI: https://doi.org/10.29271/jcpsp.2020.04.412.

\section{INTRODUCTION}

The epidemic of obesity is increasing globally. This increasing trend is showing soaring prevalence since 1980, which is almost double during last decade. ${ }^{1,2}$ According to World Health Organization in 2016, an estimated 600 million population around the globe were obese, projecting the number to reach up to 3 billion people by the year $2030 .^{3}$ Multiple factors that are making obesity pandemic include body size preference, socio-economic status, regional disparities, food marketing and westernization of lifestyle. ${ }^{4}$ According to a study, body size preference was the main source of rising obesity epidemic during the initial decades of past century when obesity was considered as a symbol of beauty, health and wealth. While obesity is a significant contributor of various comorbidities like diabetes mellitus, dyslipidemia, chronic heart diseases, musculoskeletal disorders, sleep apnea syndromes and certain type of cancers, finding an appropriate management strategy is a serious concern for healthcare providers. ${ }^{5,6}$

Multiplestrategiesincluding pharmaceutical, psychological, nutritional, surgical and complementary therapies are claiming substantial results in the management of obesity. ${ }^{7}$ But the role of exercises as effective interventional strategy has widely been accepted

Correspondence to: Batool Hassan, Ziauddin College of Rehabilitation Sciences, Ziauddin University, Plot E-40/1, Wahid Colony Block - B, North Nazimabad, Karachi, Pakistan

E-mail: hassan.batool.2016@gmail.com

Received: August 16, 2019; Revised: November 20, 2019;

Accepted: December 16, 2019

DOI: https://doi.org/10.29271/jcpsp.2020.04.412 and known for many years and has proven to be effective both in long and short term. ${ }^{8,9}$ According to the study of Gillen et al. in 2018, effectiveness of exercise in management of obesity is dependent on dosage and type of exercise; as receptivity of exercise among general population is poor and required substantial time and commitment for its performance. ${ }^{10}$ Therefore, an effective quantification of exercise is required to evaluate prescribed dosage of exercise in terms of its frequency, intensity, time and type (FITT). American College of Sports Medicine (ACSM) FITT protocol is proven to be an effective tool for quantification of exercise. ${ }^{11}$

According to an Australian-based concept of multimodal management, obesity is classified as a disease threatening the life expectancy of population, thus making it obligatory to be treated within the standard healthcare system. They also recommended tailored exercise program designed for obese population to improve adherence and provide desirable outcome within the possible duration of time. ${ }^{12,13}$ Multiple studies have focused two basic exercise regimes: aerobic exercises including walking, running, cycling, jogging etc. and resistance exercises including weight lifting that are primarily be used in the management of obesity. But the impact of these two exercises on body fat percentage; is different as aerobic exercises primarily trigger in reducing body fat percentage whereas, resistance exercises, besides reducing the body fat percentage, triggers the increase in lean mass (muscle mass). Thereby, it often causes increase in body weight. But no meta-analysis evaluating the claim of randomized controlled trial has been conducted till date. Hence, the present study is an attempt to consolidate the results of all those RCTs in which effects of aerobic and resistance exercises are compared in management of body fat mass among obese population depending on exercise protocol ranging from two months to eight months of duration. 


\section{METHODOLOGY}

Databases of Google Scholar, BioMed Central, PubMed, Cochrane and Medline were reconnoitered for purpose of research article of interest by using following keywords: Resistance exercises, aerobic exercises, obesity, exercise and obesity, body fat mass, body fat index, and body fat composition. All studies, in which effect of aerobic and resistance exercise in the management of body fat mass was determined, were procedurally scrutinized and those studies fulfilling the inclusion criteria were retrieved and comprehended in the present study.

Inclusion criteria encompass studies in which effects of aerobic and resistance exercises were determined on body fat mass of obese participants. All those studies in which combination of aerobic and resistance exercise were used, or outcome measures were other than body fat mass or studies conducted before 2010 (that were replaced by latest version of evidences) were excluded from this review.

Data abstraction and quality valuation were performed through inclusion and exclusion criteria, guided by developed uniform protocol. A data-mining form was planned to ensure data precision by combining material from studies such as first name of author, year of publication, duration of intervention, and the sample size in aerobic and resistance group (Table I).

Table I: Summary of studies used for quantitative analysis.

\begin{tabular}{|l|c|c|c|c|}
\hline Author & Study & $\begin{array}{c}\text { Aerobic } \\
\text { N }\end{array}$ & $\begin{array}{c}\text { Resistance } \\
\text { N }\end{array}$ & Training duration \\
\hline Hassannejad A et al. ${ }^{1}$ & 2017 & 20 & 20 & 3 months \\
\hline${\text { Schroeder EC et al. }{ }^{14}}$ & 2019 & 17 & 17 & 2 months \\
\hline Villareal DT et al. ${ }^{15}$ & 2017 & 40 & 40 & 6 months \\
\hline Beavers KM et al. ${ }^{16}$ & 2017 & 86 & 81 & $\begin{array}{c}6 \text { months } \\
\text { (calories restriction } \\
\text { and exercise) }\end{array}$ \\
\hline Theodorou AA et al. ${ }^{17}$ & 2016 & 15 & 11 & 8 months \\
\hline Sigal RJ et al. ${ }^{18}$ & 2015 & 74 & 75 & 6 months \\
\hline Wanderley FA et al. ${ }^{19}$ & 2015 & 24 & 19 & 8 months \\
\hline Alberga AS et al. ${ }^{20}$ & 2015 & 75 & 78 & 6 months \\
\hline Ho SS et al. ${ }^{21}$ & 2012 & 15 & 16 & 3 months \\
\hline Willis LH et al. ${ }^{22}$ & 2012 & 38 & 44 & 2 months \\
\hline
\end{tabular}

Data analysis was performed through MedCalc software. A continuous measure tool through standardized mean difference (SMD) was used to determine the pool effect at random effect model ( $I^{2}$ at $95 \%$ of $\mathrm{Cl}$ ). The data was interpreted on the basis of SMD table and forest plot using Hedge g statistics. Cohen rule of thumb was used for interpretation of findings, which states that a value of 0.2 reflects small effect, 0.5 indicates mediums and a value greater than 0.8 reveals a greater effect size. Level of heterogeneity was measured by using Cochrane $\mathrm{Q}$ and percentage of heterogeneity. $\mathrm{I}^{2}$ was determined by subtracting degree of freedom Df by Cochrane $\mathrm{Q}$ and dividing the number by Cochrane $\mathrm{Q}$ to get the value in percentage $\left(I^{2}=Q-D f / Q\right)$. Having a range of $0 \%$ to $100 \%$, $0 \%$ indicates no heterogeneity; whereas, higher value reflects higherpercentages of heterogeneity among the studies.

\section{RESULTS}

Eight hundred and five participants in 10 randomized control trials were included as part of this meta-analysis for the purpose of determining the SMD of interventional strategies. The searches were conducted from Medline, BioMed Central, PubMed, Cochrane and Google Scholar database. A total of 50 studies were identified initially. Articles were austerely examined, and all those RCTs $(\mathrm{N}=33)$ were incorporated in which effects of aerobic and resistance exercises were determined on body fat mass as a primary outcome. After initial screening, 20 articles were selected, out of which 10 articles were further screened out, based on inclusion and exclusion criteria; and finally a review of 10 RCTs was conducted and incorporated in this study.

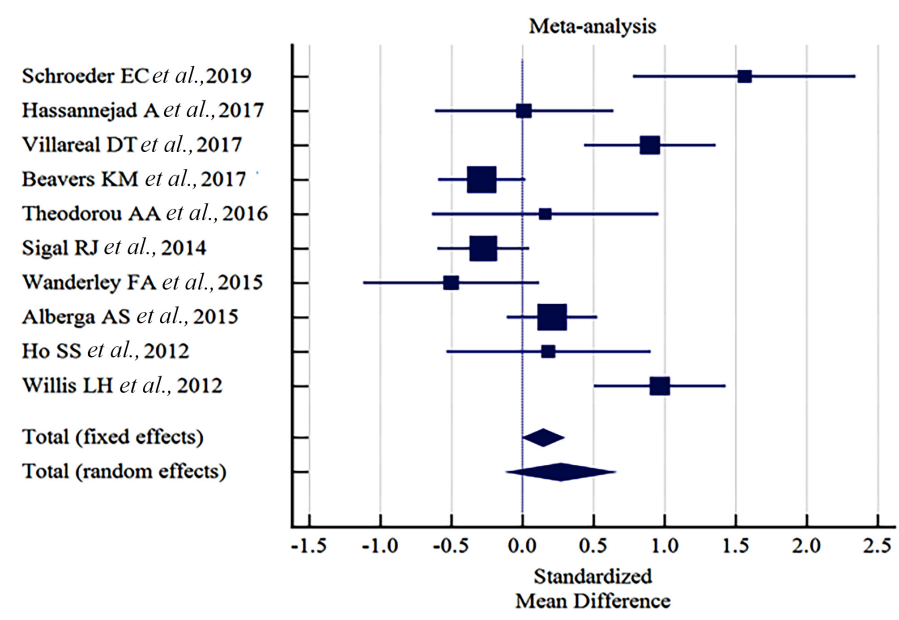

Figure 1: Forestplotillustratingtheeffects ofSMDat $95 \%$ ofCl.

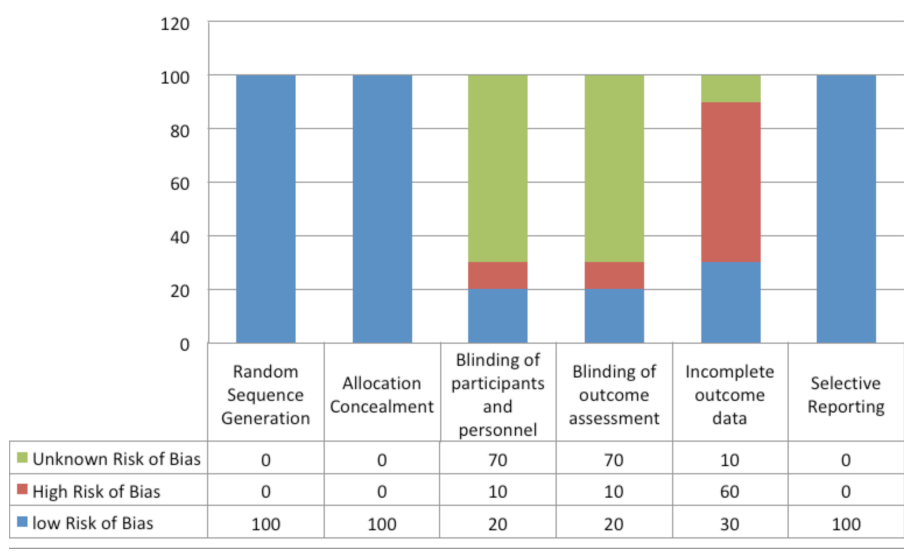

Figure 2: Authors' judgment of risk of bias assessment.

Percentage of heterogeneity was measured using $I^{2}$ test that was calculated through Cochrane Q among the SMD of the incorporated studies; as the percent values of level of inconsistency among the studies was $83.80 \%$, random effect model was used for assessing the pool effects.

The effect size was measured by using SMD hedge g statistics that revealed that resistance exercises had a mild pool affect in increasing the weight of the participants with an effect size (SMD) of 0.26 (95\% of $\mathrm{Cl}-0.09$ to 0.63$)$ calculated at random effect model, $I^{2} 83.80 \%$ ( $95 \%$ of $\mathrm{Cl} 71.76$ to 90.71 ). The combine effects of exercises on body weight on SMD as random effects models showed an effect of 0.26 ( $95 \%$ of $\mathrm{Cl}-0.09$ to 0.63 ) of resistance 
Table II: Pooled effect of intervention on outcome measure.

\begin{tabular}{|c|c|c|c|c|c|c|c|c|c|c|}
\hline \multirow{2}{*}{ Study } & \multirow{2}{*}{ N1 } & \multirow{2}{*}{ N2 } & \multirow{2}{*}{ Total } & \multirow{2}{*}{ SMD } & \multirow{2}{*}{ SE } & \multirow{2}{*}{$95 \% \mathrm{Cl}$} & \multirow{2}{*}{$\mathbf{T}$} & \multirow{2}{*}{$\mathbf{P}$} & \multicolumn{2}{|c|}{ Weight (\%) } \\
\hline & & & & & & & & & Fixed & Random \\
\hline Hassannejad A et al., 2017 & 20 & 20 & 40 & 0.0131 & 0.310 & -0.614 to 0.641 & & & 5.28 & 9.39 \\
\hline Schroeder EC et al., $2019^{14}$ & 17 & 17 & 34 & 1.562 & 0.385 & 0.778 to 2.346 & & & 3.43 & 8.24 \\
\hline Villareal DT et al., $2017^{15}$ & 40 & 40 & 80 & 0.897 & 0.233 & 0.434 to 1.360 & & & 9.38 & 10.58 \\
\hline Beavers KM et al., $2017^{16}$ & 81 & 86 & 167 & -0.284 & 0.155 & -0.590 to 0.0215 & & & 21.14 & 11.64 \\
\hline Theodorou AA et al., $2016^{17}$ & 11 & 15 & 26 & 0.160 & 0.385 & -0.635 to 0.955 & & & 3.42 & 8.24 \\
\hline Sigal RJ et al., $2014^{18}$ & 75 & 74 & 149 & -0.275 & 0.164 & -0.599 to 0.0486 & & & 18.91 & 11.54 \\
\hline Wanderley FA et al., $2015^{19}$ & 19 & 24 & 43 & -0.498 & 0.306 & -1.116 to 0.120 & & & 5.41 & 9.45 \\
\hline Alberga AS et al., $2015^{20}$ & 78 & 75 & 153 & 0.209 & 0.161 & -0.109 to 0.528 & & & 19.48 & 11.57 \\
\hline Ho SS e al., $2012^{21}$ & 16 & 15 & 31 & 0.185 & 0.351 & -0.532 to 0.902 & & & 4.12 & 8.76 \\
\hline Willis LH et al., $2012^{22}$ & 44 & 38 & 82 & 0.966 & 0.232 & 0.504 to 1.428 & & & 9.43 & 10.59 \\
\hline Total (Fixed effects) & 401 & 404 & 805 & 0.144 & 0.0712 & 0.00442 to 0.284 & 2.025 & 0.043 & 100.00 & 100.00 \\
\hline Total (Random effects) & 401 & 404 & 805 & 0.269 & 0.187 & -0.0983 to 0.636 & 1.437 & 0.151 & 100.00 & 100.00 \\
\hline
\end{tabular}

Table III: Authors' judgment about bias assessment.

\begin{tabular}{|c|c|c|c|c|c|c|}
\hline Domains & $\begin{array}{c}\text { Random } \\
\text { Sequence } \\
\text { Generation }\end{array}$ & $\begin{array}{l}\text { Distribution } \\
\text { Concealment }\end{array}$ & \begin{tabular}{|c|} 
Blinding of \\
participants and \\
personnel
\end{tabular} & $\begin{array}{l}\text { Blinding of } \\
\text { outcome } \\
\text { assessment }\end{array}$ & \begin{tabular}{|c|} 
Incomplete \\
outcome data
\end{tabular} & $\begin{array}{l}\text { Selective } \\
\text { Reporting }\end{array}$ \\
\hline Hassannejad A et at., $2017^{1}$ & $\checkmark$ & $\checkmark$ & $?$ & $\checkmark$ & $x$ & $\checkmark$ \\
\hline Schroeder EC et al., $2019^{14}$ & $\checkmark$ & $\checkmark$ & $x$ & $x$ & $\checkmark$ & $\checkmark$ \\
\hline Villareal DT et al., $2017^{15}$ & $\checkmark$ & $\checkmark$ & $?$ & $?$ & $\checkmark$ & $\checkmark$ \\
\hline Beavers KM et al., $2017^{16}$ & $\checkmark$ & $\checkmark$ & $\checkmark$ & $?$ & $\checkmark$ & $\checkmark$ \\
\hline Theodorou AA et al., $2016^{17}$ & $\checkmark$ & $\checkmark$ & $?$ & $?$ & $?$ & $\checkmark$ \\
\hline Sigal RJ et al., $2014^{18}$ & $\checkmark$ & $\checkmark$ & $\checkmark$ & $\checkmark$ & $x$ & $\checkmark$ \\
\hline Wanderley FA et al., $2015^{19}$ & $\checkmark$ & $\checkmark$ & $?$ & $?$ & $x$ & $\checkmark$ \\
\hline Alberga AS et al., $2015^{20}$ & $\checkmark$ & $\checkmark$ & $?$ & $?$ & $x$ & $\checkmark$ \\
\hline Ho SS e al., $2012^{21}$ & $\checkmark$ & $\checkmark$ & $?$ & $?$ & $x$ & $\checkmark$ \\
\hline Willis LH et al., $2012^{22}$ & $\checkmark$ & $\checkmark$ & $?$ & $?$ & $x$ & $\checkmark$ \\
\hline
\end{tabular}

exercises in increasing the weight of the participants compared to aerobic exercises, that according to Cohen rule represents mild effect of resistance exercises in soaring the body weight (Table II).

Cochrane risk of bias assessments of included studies is presented in Table III. The authors' judgment of risk of bias assessment is illustrated in Figure 2.

\section{DISCUSSION}

Results of meta-analysis revealed that resistance exercises had a mild pool affect in increasing the weight of participants with an effect size (SMD) of $0.26(95 \% \mathrm{Cl}=0.09-0.63)$ calculated at random effect model, $1283.80 \%(95 \% \mathrm{Cl}=71.76-90.71)$ in comparison to aerobic exercises performed during the duration of two to eight months of training protocol. Similarly, in the study conducted by Alberga et al. in 2015 in which it was concluded that six months' training, based on resistance exercises, increased the body weight of the participants by $0.3 \mathrm{~kg}$; whereas, the same study has also revealed that participants given intervention, based on aerobic exercises, protocol, reduced the weight by $0.1 \mathrm{~kg}$. The individual SMD of all the studies included in this meta-analysis revealed that three studies favored resistance exercises in reducing the body weight mass of the participants with an effect size of mild to moderate $(-0.28$ to -0.49$)$ after six to eight months of training protocol; whereas, the remaining seven studies favored aerobic over resistance training with an effect size of moderate to high performed during two to six months of training protocol.

It was observed from literatures that the causal effects of resistance exercise on obesity were found to be limited when compared to aerobic. According to Mohammadi HR et al. the impact of six months of training, based on aerobic exercises, increased the body fat mass of the participants with the mean difference of 5.45; but the study was not included in measuring SMD due to its quasi experimental design. ${ }^{23}$ Further it was also revealed during the analysis of the studies that although the impact of both training protocol were found to be effective for weight loss, but the response of aerobic training exclusively impact the body fat mass, whereas résistance training directly impact the lean mass. Therefore resistant 
training was found to be mild to moderately effective in reducing the body fat mass as the composition of fat mass that was reduced after the training was compensated by the increase in the lean mass that was developed during the training in the form of hypertrophy of the muscle mass. The homeostasis between the calories intake and calories burned are normally regulated by two sets of neurons located in the hypothalamus. ${ }^{24}$ Any activity that causes reduction in food intake and increase in physical activity creates a negative energy balance and cascade the central and peripheral adaptive mechanism to preserve vital function. ${ }^{25}$ This initial response of food restriction and physical activity invoke a physiological mechanism inside body to relatively reduce the resting energy expenditure, preoccupation of food and other metabolic and psychological processes ${ }^{26}$ This may often cause an increase in orexigenic signal from the brain that increases appetite and food intake that subsequently reduces the degree of weight loss that is associated with interventional strategies such as exercises programme. ${ }^{27}$ Similarly, during a weight reduce state the same mechanism of orexigenic signal may cause a weight gain ${ }^{27}$. Although the underlying principle of these responses is still unclear, but the implication is that persons who are no longer obese may not be physiologically and metabolically identical to their counterparts who were never obese. ${ }^{24}$ Hence, the relapse rate and transitional weight gain after an episode of weight loss is consistent with the concept that obesity is a chronic disease that requires persistent vigilance and maintenance.

This meta-analysis, as per the knowledge of researcher, is first of its kind that had compared the effects of two widely used exercises protocol on body fat mass of patients and tried to identify SMD at larger effects size of 805 obese patients included in 10 studies. However, the limitation includes that authors had only incorporated the effect of body fat mass in this analysis and no account had been taken to identify the impact of exercises on other parameters of obesity like body mass index (BMI) and waist hip ratio. Hence, authors recommend performing further meta-analysis in future that provides the effects of exercises on BMI and waist hip ratio on larger scale.

\section{CONCLUSION}

The study concluded that resistance exercises had a mild pool effect in increasing the weight of the participants as compared to aerobic exercises that were performed during a duration ranging from two months to eight months of conditioning.

\section{CONFLICT OF INTEREST:}

Authors declared no conflict of interest.

\section{AUTHORS' CONTRIBUTION:}

$\mathrm{BH}$ : Concept writing and interpretation of data.

SIF, UK: Critical revision and intellectual content.

AF, QA: Revision of the manuscript and questions related to integrity and accuracy are resolved.

\section{REFERENCES}

1. Hassannejad A, Khalaj A, Mansournia MA, Tabesh MR,
Alizadeh Z. The effect of aerobic or aerobic-strength exercise on body composition and functional capacity in patients with bmi $\geq 35$ after bariatric surgery a randomized control trial. Obes Surg 2017; 27:2792-801.

2. Stevens GA, Singh GM, Lu Y, Danaei G, Lin JK, Finucane MM, et al. National, regional, and global trends in adult overweight and obesity prevalence. Popul Health Metr 2012; 10:1.

3. Obesity and overweight. World Health Organization 2016. Available at: http://www.who.int/mediacentre/factsheets/ fs311/en/ (last accessed December 2016).

4. Blüher M. Obesity: Global epidemiology and pathogenesis. Endocrinology 2019; 27:288-98.

5. Mandviwala T, Khalid U, Deswal A. Obesity and cardiovascular disease a risk factor or a risk marker. Curr Atheroscler Rep 2016; 18:21.

6. Lim SP, Arasaratnam P, Chow BJ, Beanlands RS, Hessian RC. Obesity and the challenges of noninvasive imaging for the detection of coronary artery disease. Can J Cardiol 2015; 31:223-6.

7. Neff KJ, Ferrannini E, Roux CW. Treatment of obesity bariatric surgery. Int Textbook Diabetes Mellit 2015; 17:505-18.

8. de Roon M, van Gemert WA, Peeters PH, Schuit AJ, Monninkhof EM. Long-term effects of a weight loss inter-vention with or without exercise component in post-menopausal women a randomized trial. Prev Med Rep 2017; 5:118-23.

9. McNeil J, Farris MS, Ruan Y, Merry H, Lynch BM, Matthews CE, et al. Effects of prescribed aerobic exercise volume on physical activity and sedentary time in postmenopausal women a randomized controlled trial. Int J Behav Nutr Phys Act 2018; 15:27.

10. Gillen JB, Gibala MJ. Interval training a time-efficient exercise strategy to improve cardiometabolic health. Appl Physiol Nutr Metab 2018 26; 43:iii-v.

11. Keating SE, Johnson NA, Mielke GI, Coombes JS. A systematic review and meta-analysis of interval training versus moderate-intensity continuous training on body adiposity. Obes Rev 2017; 18:943-64.

12. Maillard F, Pereira B, Boisseau N. Effect of high-intensity interval training on total abdominal and visceral fat mass a meta-analysis. Int J Sports Med 2018; 48:269-88.

13. Forgione N, Deed G, Kilov G, Rigas G. Managing obesity in primary care breaking down the barriers. Adv Ther 2018; 35:191-8.

14. Schroeder EC, Franke WD, Sharp RL, Lee DC. Comparative effectiveness of aerobic, resistance and combined training on cardiovascular disease risk factors a randomized controlled trial. PLoS One 2019; 14:e0210292.

15. Villareal DT, Aguirre L, Gurney AB, Waters DL, Sinacore DR, Colombo $\mathrm{E}$, et al. Aerobic or resistance exercise or both in dieting obese older adults. N Engl J Med 2017; 376: 1943-55.

16. Beavers KM, Ambrosius WT, Rejeski WJ, Burdette JH, Walkup $M P$, Sheedy JL, et al. Effect of exercise type during intentional weight loss on body composition in older adults with obesity. Obesity 2017; 25:1823-9.

17. Theodorou AA, Panayiotou G, Volaklis KA, Douda HT, Paschalis $\mathrm{V}$, Nikolaidis MG, et al. Aerobic, resistance and combined training and detraining on body composition, muscle strength, lipid profile and inflammation in coronary artery disease patients. PLOS One 2016; 24:171-84.

18. Sigal RJ, Alberga AS, Goldfield GS, Prud'homme D, Hadjiyan- 
nakis S, Gougeon R, et al. Effects of aerobic training, resistance training or both on percentage body fat and cardiometabolic risk markers in obese adolescents the healthy eating aerobic and resistance training in youth randomized clinical trial. JAMA Pediatr 2014; 168:1006-14.

19. Wanderley FA, Oliveira NL, Marques E, Moreira P, Oliveira J, Carvalho J. Aerobic versus resistance training effects on health-related quality of life body composition and function of older adults. J Appl Gerontol 2015; 34:NP143-65.

20. Alberga AS, Prud'homme D, Sigal RJ, Goldfield GS, Hadjiyannakis $S$, Phillips $P$, et al. Effects of aerobic training, resistance training or both on cardiorespiratory and musculoskeletal fitness in adolescents with obesity the hearty trial. Appl Physiol Nutr Metab 2015; 41:255-65.

21. Ho SS, Dhaliwal SS, Hills AP, Pal S. The effect of 12 weeks of aerobic resistance or combination exercise training on cardiovascular risk factors in the overweight and obese in a randomized trial. BMC Public Health 2012; 12:704.

22. Willis LH, Slentz CA, Bateman LA, Shields AT, Piner LW, Bales
CW, Houmard JA, Kraus WE. Effects of aerobic and or resistance training on body mass and fat mass in overweight or obese adults. J Appl Physiol 2012; 113: 1831-7.

23. Mohammadi HR, Khoshnam MS, Khoshnam E. Effects of different modes of exercise training on body composition and risk factors for cardiovascular disease in middle-aged men. Int J Prev Med 2018; 9:9.

24. Heymsfield SB, Wadden TA. Mechanisms, pathophysiology and management of obesity. N Engl J Med 2017; 376:254-66.

25. van der Klaauw AA, Farooqi IS. The hunger genes pathways to obesity. Cell 2015; 161:119-32.

26. Leibel RL, Seeley RJ, Darsow T, Berg EG, Smith SR, Ratner R. Biologic responses to weight loss and weight regain report from an american diabetes association research symposium. Diabetes 2015; 64:2299-309.

27. Thomas DM, Bouchard C, Church T, Slentz C, Kraus WE, Redman LM, et al. Why do individuals not lose more weight from an exercise intervention at a defined dose an energy balance analysis. Obes Rev 2012; 1:835-47. 